BANCA D'ITALIA

E U R O S I S T E M A

Questioni di Economia e Finanza

(Occasional Papers)

Net employment growth by firm size and age in Italy

by Francesco Manaresi 

13 BANCA D'ITALIA

E U ROS I S T E M A

\section{Questioni di Economia e Finanza}

(Occasional papers)

Net employment growth by firm size and age in Italy

by Francesco Manaresi

Number 298 - November 2015 
The series Occasional Papers presents studies and documents on issues pertaining to the institutional tasks of the Bank of Italy and the Eurosystem. The Occasional Papers appear alongside the Working Papers series which are specifically aimed at providing original contributions to economic research.

The Occasional Papers include studies conducted within the Bank of Italy, sometimes in cooperation with the Eurosystem or other institutions. The views expressed in the studies are those of the authors and do not involve the responsibility of the institutions to which they belong.

The series is available online at www.bancaditalia.it .

ISSN $1972-6627$ (print)

ISSN 1972-6643 (online)

Printed by the Printing and Publishing Division of the Bank of Italy 


\title{
NET EMPLOYMENT GROWTH BY FIRM SIZE AND AGE IN ITALY
}

\author{
by Francesco Manaresi*
}

\begin{abstract}
We study how net employment growth rates differ by firm age and size. For this purpose, we exploit a long panel dataset collecting information for all Italian private firms with at least one employee. We find that firm size is not a crucial determinant of firm growth, once age is controlled for. Firms in their early years of life (up to 3 years) display higher growth rates and slightly higher exit rates than older firms. This up-or-out dynamic of Italian firms seem subdued if compared with the US, the other country for which a similar analysis is available. We also exploit the long time series to identify which types of firms are hit the most during economic downturns. Results show that older firms reduce net employment growth the most. The impact on younger firms seem partially cushioned by stronger selection at entry. Conditional on age, size turns out not to be significantly correlated with the drop in net employment growth rates during downturns.
\end{abstract}

JEL Classification: D22, L25.

Keywords: employment growth, firm size, firm age.

\section{Contents}

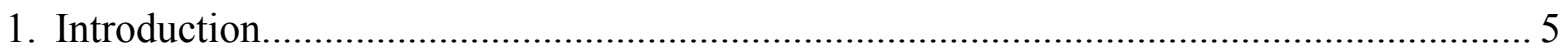

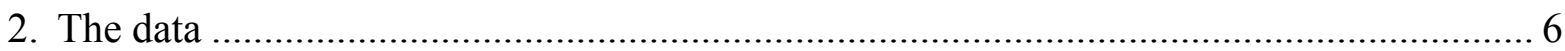

3. Who creates jobs? The role of firm size and age ........................................................ 7

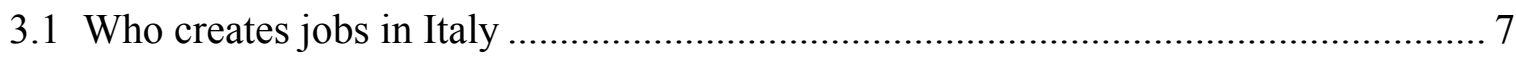

3.2 Evidence on (lack of) up-or-out dynamics among Italian firms............................... 8

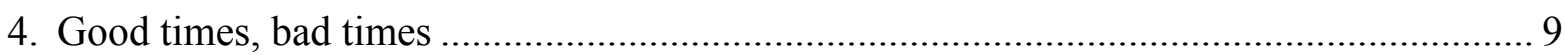

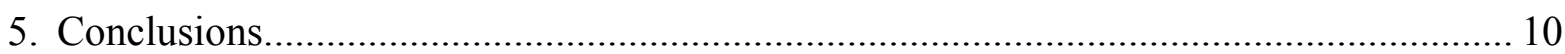

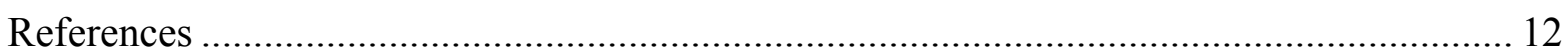

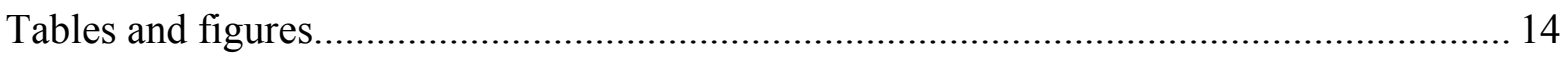

* Bank of Italy, Structural Economic Analysis - Labor Market Division. 



\section{Introduction}

Aggregate changes in employment result from the process of job creation and destruction by individual firms. A large literature, dating back at least to Birch (1981), found that small firms display higher net employment growth rates than bigger ones, contrary to Gibrat's Law. More recently several studies (Haltiwanger, Jarmin and Miranda 2013 QJE; Criscuolo, Gal, and Menon 2014; Lawless 2014) have emphasized that this empirical regularity may be spuriously driven by the correlation between size and age. Using longitudinal data from US, Haltiwanger et al. (2013) found that, once controlled for age, the correlation between size and growth vanishes: if anything, it becomes positive. They, thus, turned their attention to analyzing the role of firm age. Young firms contribute disproportionally to job creation, and a key role is associated with firm births: the birth of new firms contribute substantially to both gross and net employment growth. Also, firms display higher job creation rates during their initial years of life (up to five years old). At this stage of life, yet, the process of job destruction is also very intense, driven by significant exit rates. This "up-or-out" dynamic has been confirmed by Criscuolo et al. (2014), exploiting data from National Statistical Institutes of several OECD countries, and by Lawless (2014) for Ireland.

These dynamics can be explained by models of "passive learning" à la Jovanovic (1982), in which a firm enters a market with imperfect knowledge of its own efficiency levels, or by models that allow for firms to increase their productivity overtime by investing resources (as in Ericson and Pakes 1995, Klette and Kortum 2004, and Hsieh and Klenow 2014). These model attribute to "up-or-out" dynamics a crucial role in productivity growth, through the process of market selection.

In this note, we exploit the longitudinal dataset covering all firms with at least one employee, administered by the Italian Social Security Institute (INPS). This dataset contains complete information on firm entry, exit, average yearly employees, and wages for the period 1991-2009. We focus on firms active in manufacturing, construction, and private services.

We start by replicating the analyses of Haltiwanger et al. (2013). Consistently with previous literature, we find that the negative correlation between size and firm growth disappears, once we control for age. If anything, very small firms (lower than 5 employees) display lower net employment growth than all other size groups. Conversely, firms younger than three years old display higher growth rates both unconditionally and conditionally on size (and unobserved heterogeneity at the year and sector level). High net employment growth in the early years of life are accompanied by some signs of a stronger selection, as measured by exit rates, with respect to older firms. From three years of age onwards, though, the up-orout dynamic ends: net employment growth remains almost constant over the rest of the age distribution. These patterns can be compared with those highlighted by Haltiwanger et al. (2013) for the US: there, the up-or-out dynamic continues to be significant until at least 10 years of age. For Ireland, Lawless (2014) finds that younger firms continue to display higher net employment growth rates and higher exit rates up until 5 years of age. A lower up-or-out dynamics is consistent with the larger share of old firms that has been recently highlighted for Italy, in comparison with several OECD countries (Criscuolo et al. 2014).

As a second exercise, we enrich the age-size analysis by comparing net employment growth in downturns and normal times, exploiting the long time-series available. We identify downturns using two alternative methods (namely, negative sector-specific value added growth - used as a continuous variable or as a dummy equal to 1 when it is negative - and creating a dummy for recession years). We find that smaller and bigger firms are similarly hit by downturns, once properly controlled for age. We also find evidence of a positive selection of new entrants during downturns, which partially mitigates the negative 
effect on net employment growth. Indeed, while net job employment growth rates declines significantly in all age groups, the drop is weaker for firms in the early stages of life (1-2 years old). This is accompanied by lower entry rates with respect to normal times and higher exit rates in all age groups, but particularly among older firms.

These results are novel for the case of Italy but also extremely preliminary and limited in many respects. In particular, our analysis still faces several empirical limitations. To cite a few of them, we do not observe non-employee workers (such as "parasubordinati"), whose utilization may be correlated with firm age; our findings for incorporated firms may be countered by unincorporated ones; we cannot control (yet) for merge and divestments of firms. Although most of these caveats are shared by many other empirical studies, their implications for our analysis shall not be underestimated. ${ }^{1}$

The note is structured as follows. Section 2 presents the data. Section 3 replicates Haltiwanger et al. (2013), showing that in Italy (as in the US) net employment growth is not correlated with size, once we control for age, and that younger firms display significantly higher growth rates. It also discusses the up-orout dynamic of Italian firms, as compared with the one of US firms. Section 4 studies whether and to what extent economic downturns impact differently on firms, according to their size and age. Section 5 concludes.

\section{The data}

From INPS we received data on all Italian firms active in the private non-agricultural sector, with at least one employee, for the period 1991-2009. ${ }^{2}$ For each of the 4,107,815 individual firms in our dataset, we observe its year of entry and exit, as well as the average yearly number of employees. ${ }^{3}$

An important caveat is that the available measure of entry (exit) of firms encompasses both "true" births (deaths) and results of merge and acquisition (divestment) processes. This is potentially problematic, as the intensity of these processes may differ by size, age, and/or business cycle conditions. ${ }^{4}$

For each firm in each year, we compute the net employment growth rate proposed by Davis et al. (1996). Formally, let $L_{t}$ be firm's average employment in year $t$, the net employment growth is then equal to:

$$
N E G_{t}=2 \frac{\Delta L_{t}}{L_{t}+L_{t-1}}
$$

this indicator has two peculiarities which make it particularly suitable for analyzing the role of firm dynamics in net employment growth. First, it encompasses net employment growth both on the extensive and intensive margin. Indeed, it has support $[-2,2]$, taking value -2 when the firm exit $\left(L_{t}=0\right)$, and 2 when

\footnotetext{
${ }^{1}$ See Geurts and Van Biesebroeck (2014) for a discussion of the problems posed by merge-and-acquisitions and divestments in analyzing job creation and firm dynamics.

${ }^{2}$ The data covers also years 1990 and 2010. Yet, for these two years we do not have reliable information on entry and exit.

${ }^{3}$ We also have information on yearly total wages paid by the firm. Yet, they are provided net of amounts paid according to wage guarantee schemes. Until 2005, this schemes were available only for medium and large firms in the manufacturing and construction sectors. They were used mostly as a measure to hoard labor during downturns. These facts may induce measurement errors, likely to be correlated with both firm size and business cycle conditions, which prevent us to exploit this additional information.

${ }^{4}$ Additional efforts are thus needed to improve our measure of entry/exit in the INPS data. One promising strategy would be to work together with INPS to match the dataset with information from the Chambers of Commerce.
} 
the firm enters $\left(L_{t-1}=0\right)$. Second, by averaging size at the denominator over two periods, it avoids biases due to regression-to-the-mean effects (Friedman 1992).

Table 1 summarizes the main descriptive statistics of the dataset. Average entry rate is around $10 \%$, slightly higher than the exit rate; the average firm is 9.4 years old, and employed 7.5 individuals over the year. Finally, the average yearly net employment growth rate is $4.3 \%$.

Figure 1 shows the evolution of the entry/exit rates and total NEG over the period. Net employment growth looks strongly correlated with entry rates, rather than with exit rates: in Section 3 we explain this stylized fact with the critical role of firms in early years of age (up to 3 years old) as contributors of net employment growth. In addition, net of two peculiar spikes in 1995 and 2007 which, according to preliminary analyses may be driven by improvements in data collection by INPS, all series display a certain degree of correlation with the business cycle. Indeed, entry rates and net employment growth decline during the downturns of 1992-1993 and 2003, as well as during the Great Recession of 2008-2009. Exit rates increased both in the early 1990s and during the 2008-2009 period, while they seem less affected by the 2002-2003 recession.

\section{Who creates jobs? The role of firm size and age}

\subsection{Who Creates Jobs in Italy}

Our first objective is to understand the relationship between net employment growth and firm size and age. For this purpose, we follow the methodology developed by Haltiwanger et al. (2013) and regress net employment growth at firm level on size group dummies alone, on age group dummies alone, and on both groups together. The inclusion of both classes in the regression is performed either additively, as a simple two-way model, or fully interacting age and size classes together. In principle, the fully interacting model is the best choice, because it yields an unbiased estimate of the conditional means in each age-size cell regardless of the distribution of the dependent variable (Angrist and Pischke 2009). Yet, the results cannot be easily appreciated by readers, as they are composed of 143 different conditional means. For this reason, in this paper we are going to provide visual evidence of the results using the simpler two-way model without interactions. We discuss results from fully saturated models in the text whenever they differ qualitatively from the two-way model, or whenever they highlight interesting patterns. All regression results are available upon request.

All models have been performed including and excluding sector (2-digits ISIC Rev.1.1) and year fixed effects. Again, to ease the interpretation of the results, we focus our discussion on models that exclude those additional controls. Yet, their inclusion do not change the sign and significance of any qualitative pattern that we discuss. Inference is always based on standard errors which are robust to serial correlation at the sector level, allowing also for province level serial correlation does not change the statistical significance of our results. To ease the exposition, all results are plotted in graphs. All the patterns that we will comment in the text are statistically significant at $p<0.01$, unless differently specified.

The solid blue line in Figure 2 reports average net employment growth rates by size deciles obtained without controlling for age. The result is clearly in contrast with Gibrat's law, as firms with less than 9 employees display higher net employment growth rates than bigger firms. We then include in the regression the dummies for age classes, and plot the estimated coefficient for size classes. The resulting pattern (dashed red line) is strikingly different: net employment growth rates are significantly lower for firms with less than 5 employees, and do not change significantly over the rest of the size distribution. This 
reversion of the Gibrat's law rejection is also shared by Haltiwanger et al. (2013). Figure 3 reports the results obtained for US in their paper: by conditioning on age, firm growth becomes increasing in "current average size" (i.e. our definition of size).

To sum up, in our data, the negative correlation between size and growth seem to be induced by the effect of age, a result shared by Lawless (2014) for Ireland, and by Geurts and Van Biesebroeck (2014) for Belgium. This result is also consistent with Lotti, Santarelli and Vivarelli (2009), who found that the relationship between size and growth does not reject Gibrat's law predictions, once survival of firms over time is adequately controlled for.

The results obtained induce us to study how net employment growth rates differ between age cohorts. Figure 4 shows average net employment growth by age groups, unconditional (solid blue line) and conditional (red dashed line) on dummies for size groups. A downward concave trend can be appreciated using both models. Notably, net employment growth is significantly higher during the first two years of life. Starting from the third year of age, yet, net employment growth rates remain ultimately flat over the age distribution. To study more in depth these patterns, we introduce the concept of up-or-out dynamics.

\subsection{Evidence on (lack of) up-or-out dynamics among Italian firms}

We define an up-or-out dynamic in an age cohort, as the contemporaneous presence of high exit rates and high net employment growth rates among firms that do not exit (survivor firms, henceforth). This dynamic can be interpreted using models in which firms display passive or active learning of their actual productivity (Jovanovic 1982, Ericson and Pakes 1996, and Klette and Kortum 2004). ${ }^{5}$ In all these models, the up-or-out dynamics contributes substantially to productivity growth.

We start by comparing net employment growth by age groups (controlling for size) among all firms and survivor firms only. Results are displayed in Figure 5: obviously, net employment growth rates are always higher if we restrict to survivor firms (we are de facto excluding all firms for which $N E G_{i t}=-2$ ), yet the curve does not change its shape significantly. Again, only the first two deciles (corresponding to the first 2 years of age) display higher net employment growth, while they remain unchanged over the rest of the age distribution. This pattern differs markedly from the available evidence for the US, where, conditional on surviving, net employment growth decline steadily over the age distribution up until 10 years old (see Figure 6 here, that reports Figure 4.B, p. 357 from Haltiwanger et al. (2013)).

We continue our analysis by looking at exit rates by age, i.e. the other side of the up-or-out dynamic, in Figure $7 .{ }^{6}$ Once we do not control for size (solid blue line) we observe declining exit rates over the age distribution (i.e., a declining hazard function). This pattern is, however, confounded by the negative correlation between age and size. The dashed red line shows that, once we condition on size, exit rates by age differ much less: it declines by less than 5 percentage points over the age distribution. It is useful to compare this pattern with the one observed in the US by Haltiwanger et al. (2013), which is reported in Figure 8. Also in the US, the decline in exit rates over the age distribution becomes much less steeper once size is controlled for. The decline is similar to the one experienced by Italian firms, if measured in

\footnotetext{
${ }^{5}$ See Foster, Haltiwanger and Syverson (2012) for a model in which firms learn actively about their demand.

${ }^{6}$ Here, age 1 is omitted from the results (but not from the regressions) because, by data construction, firms exit at least one year after entry.
} 
percentage points (around 6.5 percentage points from age 2 to age 16), while it is much more pronounced if measured relative to initial exit rates.

The evidence that in Italy the age distribution of net employment growth rates among survivors is flatter and the decline in exit rates, again over the age distribution, is less pronounced than in the US calls for some sort of a structural explanation. Excluding a different sectorial composition ${ }^{7}$ or a larger firm size at entry in Italy ${ }^{8}$, it is likely that the process of selection of firms in and out of the market and the mechanisms driving the growth of young firms are functioning in Italy worse than in the US. Considering the relevance of young firm dynamics for overall growth of employment and productivity in the US (Decker, Haltiwanger, Jarmin and Miranda 2014), these Italian features could be strong obstacles to economic development.

Notice, in addition, that this pattern is also consistent with Italian firms being on average older than their US counterparts. Indeed, recent evidence by Criscuolo et al. (2014) show that the share of old firms (>10 years of age) in Italy is larger than almost all countries in their study, including US, with the exception of Finland and Japan.

Finally, an interesting comparison can be made with respect to the earlier work of Bianco and Sestito (1992), who used the INPS dataset for years 1985-1990. The decline in exit rates over the age distribution they found (unconditional with respect to size) is somehow comparable to our results: it declines by around 10 percentage points, from its top of roughly $19 \%$ for firms aged 3 (see Figure 9 , which reports Figure " $b$ " from Bianco and Sestito, 1992). This provides some evidence of the stability of the process of firm selection and exit over time.

\section{Good times, bad times}

We now compare how net employment growth rates change during recessions with respect to normal times, and we distinguish this effect by firm size and age. The existing evidence on different responsiveness by size and age of firms to economic downturns is still inconclusive, and only related to the US.

Fort, Haltiwanger, Jarmin, and Miranda (2013) provide a good review of the main results of this literature. To sum it up, we may say that most of the literature focused on firm size solely, and most of these studies found that smaller firms are more significantly hit by economic downturns (Gertler and Gilchrist 1994, Moscarini and Postel-Vinay 2012), while some found that there is no particular difference in the response of small firms during recessions (Chari et al. 2007). The few papers that dealt directly with the role of firm age (Davis and Haltiwanger 2001, Fort et al. 2013) found that younger firms are hit disproportionally by recessions.

To study how recessions impact differently according to firm age and size, we exploit the long time series available in the INPS dataset (from 1991 to 2009), and we regress a firm's net employment growth rate on a full interaction of age dummies, size dummies, and a dummy equal to 1 if there is a downturn.

For our baseline results, we define a sector (2-digits ISIC Rev1.1) to be in downturn in a specific year if its growth rate of value added (from National Accounts) is negative. We include sector and year fixed-effects. All results of the fully interacted model are available upon request. Here, we present evidence of a simpler

\footnotetext{
${ }^{7}$ Sectorial differences are unlikely to drive the results: indeed, (i) we condition on sector fixed-effects; and (ii) net employment growth rates and exit rates are flatter in Italy with respect to the US also within sectors.

${ }^{8}$ Existing evidence show that, if anything, Italian start-ups are smaller than their US counterparts (Criscuolo et al. 2014).
} 
two-way model interacted with the downturn dummy. The patterns we comment are perfectly consistent with the results of the fully interacted model.

Figure 10 reports the estimated average net employment growth by size groups, distinguishing between downturns and normal times. Overall, the pattern looks very similar. Only for firms with 1 employee is the estimated coefficient negative and significant. In most of other cases recessions do not affect net employment growth by size, once we control for firm age.

Figure 11 plots net employment growth rates by age groups in downturns and normal times. In this case, a significant drop during downturns can be appreciated. In addition, this drop seems stronger for firms older than 2. We study more in detail these differences in Figure 12, where we plot the average percentage change in net employment growth rate in downturns relative to normal times. ${ }^{9}$ We also include results obtained by using two different methods to identify downturns. First, we create a dummy $=1$ in the years of the three main cyclical downturns that hit Italy during the period of analysis: 1992-1993, 20022003, and 2008-2009. ${ }^{10}$ Second, we treat sector VA growth rate as a continuous variable, and we interact it with age and size dummies. Using all three methods, net employment growth rate is significantly less affected among firms that are less or equal to 2 years of age.

This effect is partly driven by a lower impact of downturns on exit rates of young firms. As shown in Figure 13, exit rates increase during downturns less for firms aged 2 than for older ones. ${ }^{11}$ This effect is also accompanied by lower entry rates during downturns. This fact has been highlighted previously, when commenting Figure 1: indeed, in that Figure it is apparent that entry rates decline in 1992-1993, in 2003, and in 2008-2009. More formally, we tested for a significant correlation between downturns and entry rates by estimating a logit model for the dummy $=1$ if the firm entered in that year on a dummy $=1$ if the firm experienced a downturn, controlling for sector and (whenever possible) year fixed effects. As expected, entry rates are negatively and significantly correlated with downturns (as measured using either negative sector value added growth or the simpler year-of-recession dummy). ${ }^{12}$

These patterns are consistent with downturns inducing a stronger selection at entry and among younger firms. This positive selection reduce the impact of the downturn on the net employment growth of firms who enter and (possibly) are able to survive.

\section{Conclusions}

The role of young firms in the process of job creation and destruction has been highlighted by a recently growing literature. In this paper we are able to replicate several of its findings using Italian data. Yet, the up-or-out dynamic, that all standard models of firm dynamics highlight as a crucial trigger of productivity growth, seem particularly subdued in Italy. We also find that firms in the first two years of age are significantly less affected by downturns with respect to older firms. The impact of downturns do not seem to be correlated with firm size, once age is controlled for.

\footnotetext{
${ }^{9}$ We omit the results for the first year of age, as its net job creation rate is by construction equal to 2 in both cases.

${ }^{10}$ This definitions seem rather consistent with the previous one: around $50 \%$ of the sector-specific downturns identified according to the first method take place in the six years identified according to this method.

${ }^{11}$ Note that here the difference are measured in percentage terms with respect to normal times levels (not in percentage points) to ease comparison, because exit rates are (slightly) larger among younger firms in normal times.

${ }^{12}$ The estimated coefficients are -0.054 for the sector growth rate method $(p<0.001)$, and -0.047 for the year-ofrecession method $(p<0.01)$.
} 
Further analyses are needed to (i) empirically test whether these patterns are confirmed using the whole census of Italian firms, excluding "fake" entry and exit (due to M\&A or divestments) from the sample, and including non-waged labor input; (ii) theoretically study the link between the up-or-out dynamic, allocative efficiency, and productivity growth; (iii) causally identify factors that hinder market selection during the early years of life of the firm. 


\section{References}

Angrist, J. and R. Pischke (2009), Mostly harmless econometrics, Princeton University Press.

Bianco, M. and P. Sestito (1992), Entry and growth of firms: evidence for the Italian case, Proceedings of the Conference on "Birth and Start-up of Small Firms", Milan.

Chari, V.V., L. Christiano, and P. Kehoe (2007), The Gertler-Gilchrist evidence on small and large firm sales, mimeo.

Criscuolo, C., P. Gal and C. Menon (2014), The dynamics of employment growth: new evidence from 18 countries, OECD Science, Technology and Industry Policy Paper no. 14.

Davis, S. and J. Haltiwanger (2001), Sectoral job creation and destruction responses to oil price changes and other shocks, Journal of Monetary Economics, December.

Davis, S., J. Haltiwanger, and S. Schuh (1996), Job creation and destruction, MIT Press.

Decker, R., J. Haltiwanger, R. Jarmin and J. Miranda (2014), The Role of Entrepreneurship in US Job Creation and Economic Dynamism, Journal of Economic Perspectives, 28, 3, 3-24.

Ericson, R. and A. Pakes, (1995), Markov-perfect industry dynamics: a framework for empirical work, Review of Economic Studies, 62, 671-698.

Fort, T., J. Haltiwanger, R. Jarmin, and J. Miranda (2013), How firms respond to business cycles: the role of firm age and firm size; NBER Working Paper no. 19134.

Friedman, M. (1992), Do old fallacies ever die?, Journal of Economic Literature, 30, 2129-2132.

Gertler, M. and S. Gilchrist (1994), Monetary policy, business cycle, and the behavior of small manufacturing firms, Quarterly Journal of Economics, 109(2), 309-340.

Geurts, K. and J. Van Biesebroeck (2014), Job creation, firm creation, and de novo entry, mimeo.

Haltiwanger, J. R. Jarmin, and J. Miranda (2013), Who creates jobs? Small versus large versus young, Review of Economics and Statistics, 95(2), 347-361.

Hsieh, C. and P. Klenow (2014), The life cycle of plants in India and Mexico, Quarterly Journal of Economics, $129,1035-1084$.

Jovanovic, B. (1982), Selection and the evolution of industry, Econometrica, 50, 649-670.

Klette, T.J. and S. Kortum (2004), Innovating firms and aggregate innovation, Journal of Political Economy, 112(51).

Lawless, M. (2014), Age or size? Contributions to job creation, Small Business Economic Journal, 42, 815830.

Lotti, F., E. Schiantarelli and M. Vivarelli (2009), Defending Gibrat's Law as a long-run regularity, Small Business Economic Journal, 32, 31-44. 
Moscarini, G. and F. Postel-Vinay (2012), The contribution of large and small employers to job creation in times of high and low unemployment, American Economic Review, 102(6), 2509-2539. 
Table 1. Descriptive Statistics

\begin{tabular}{lcccccc} 
& Mean & St.Dev. & Median & Min & Max & No. of Obs. \\
\hline Entry Rate & 0.104 & 0.306 & 0 & 0 & 1 & $27,279,260$ \\
Exit Rate & 0.098 & 0.298 & 0 & 0 & 1 & $27,279,260$ \\
Age & 9.432 & 9.110 & 6 & 0 & 109 & $27,279,260$ \\
Employees & 7.449 & 139.148 & 2 & 0.083 & 11780.8 & $27,279,260$ \\
Net Empl. Growth Rate & 0.043 & 1.009 & 0 & -2 & 2 & $27,279,260$
\end{tabular}


Figure 1. Entry rates, exit rates, net employment growth rates -1991-2009.

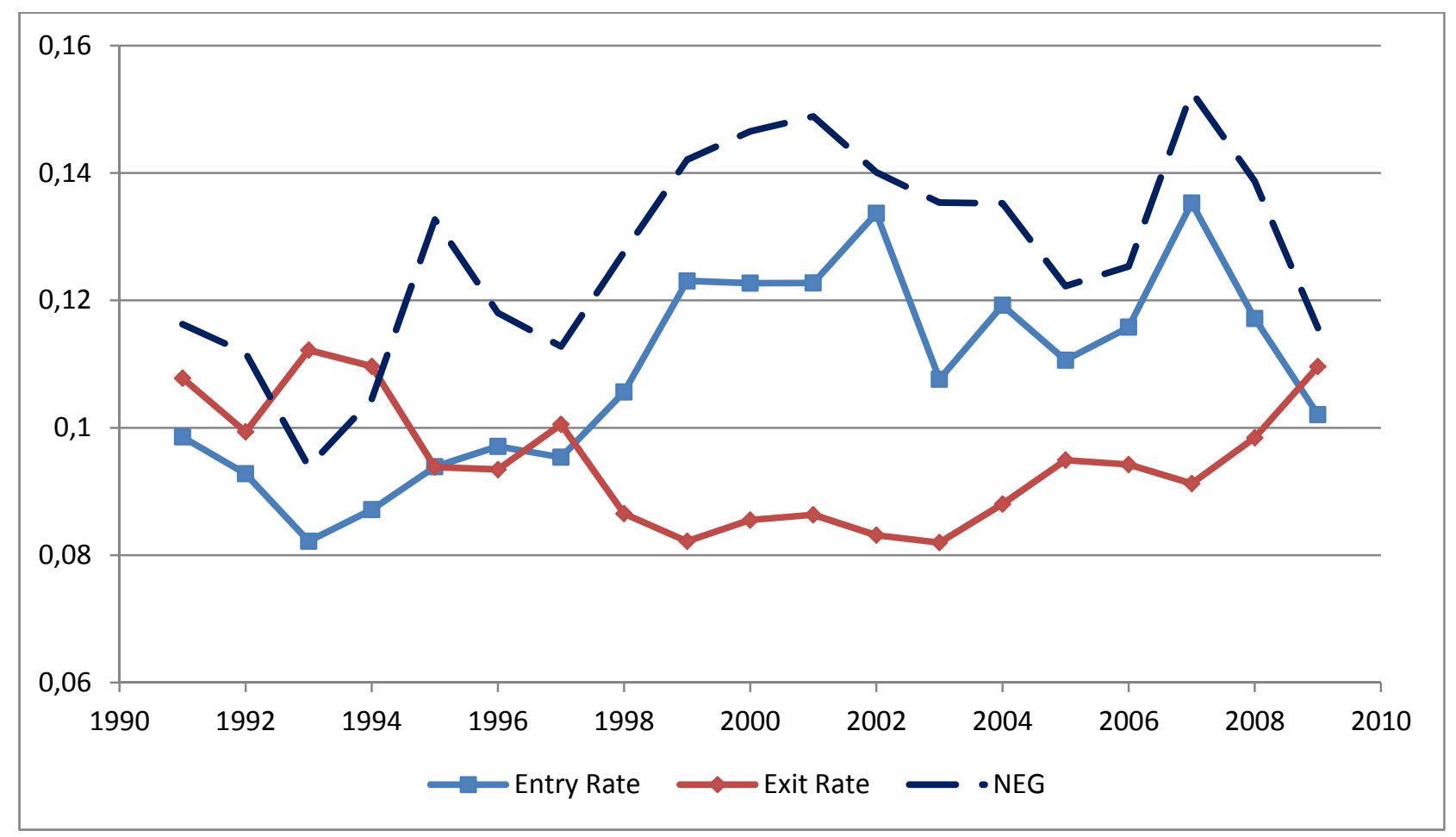

Source: INPS. 
Figure 2. Net employment growth by size - ref. category: firms with 1 employee

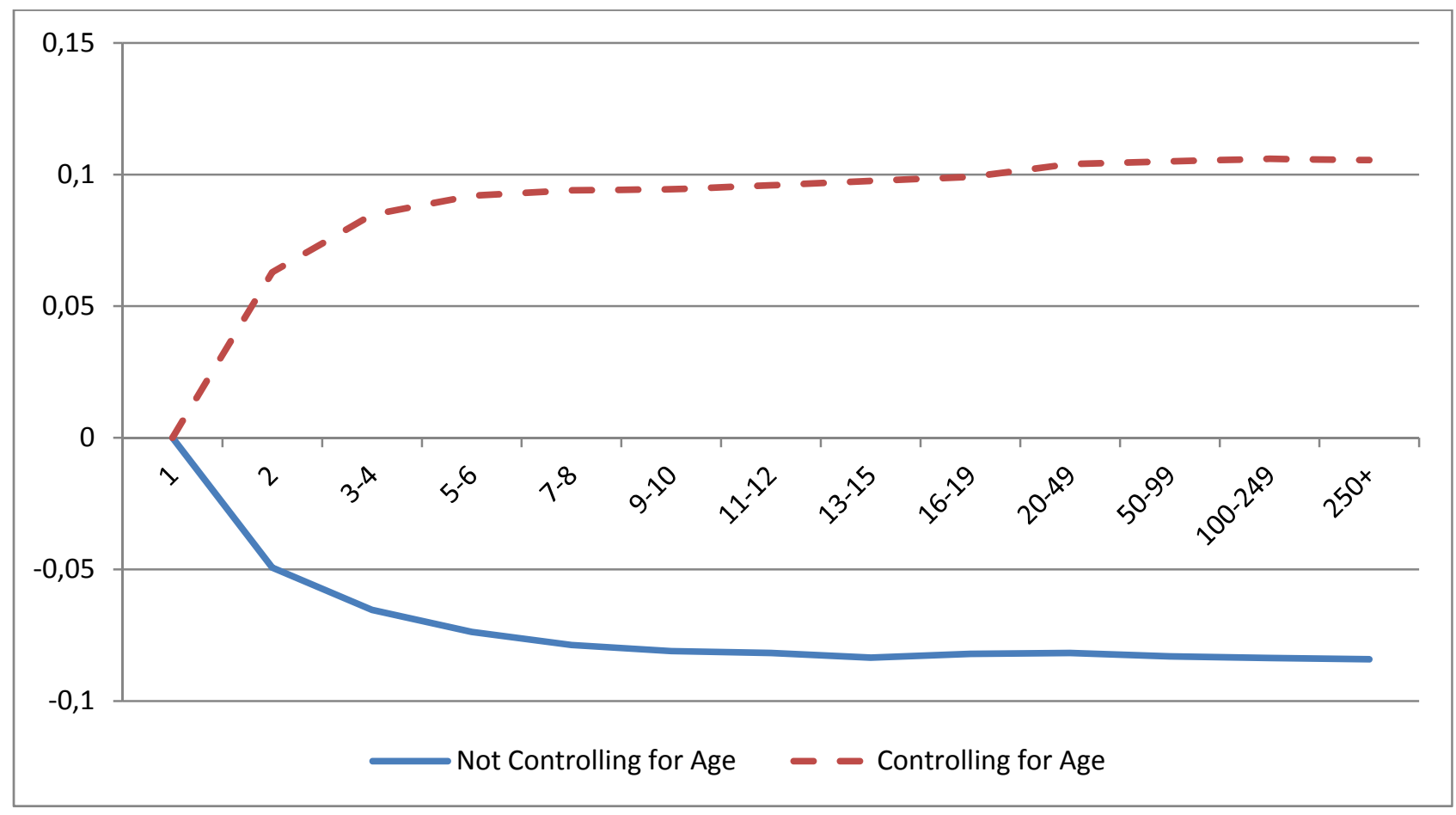

Source: INPS. 
Figure 3. Net employment growth in the US, Haltiwanger et al. (2013) - Figure 2, p. 356 - ref. category: firms with $500+$ employees

\section{A. All Firms}

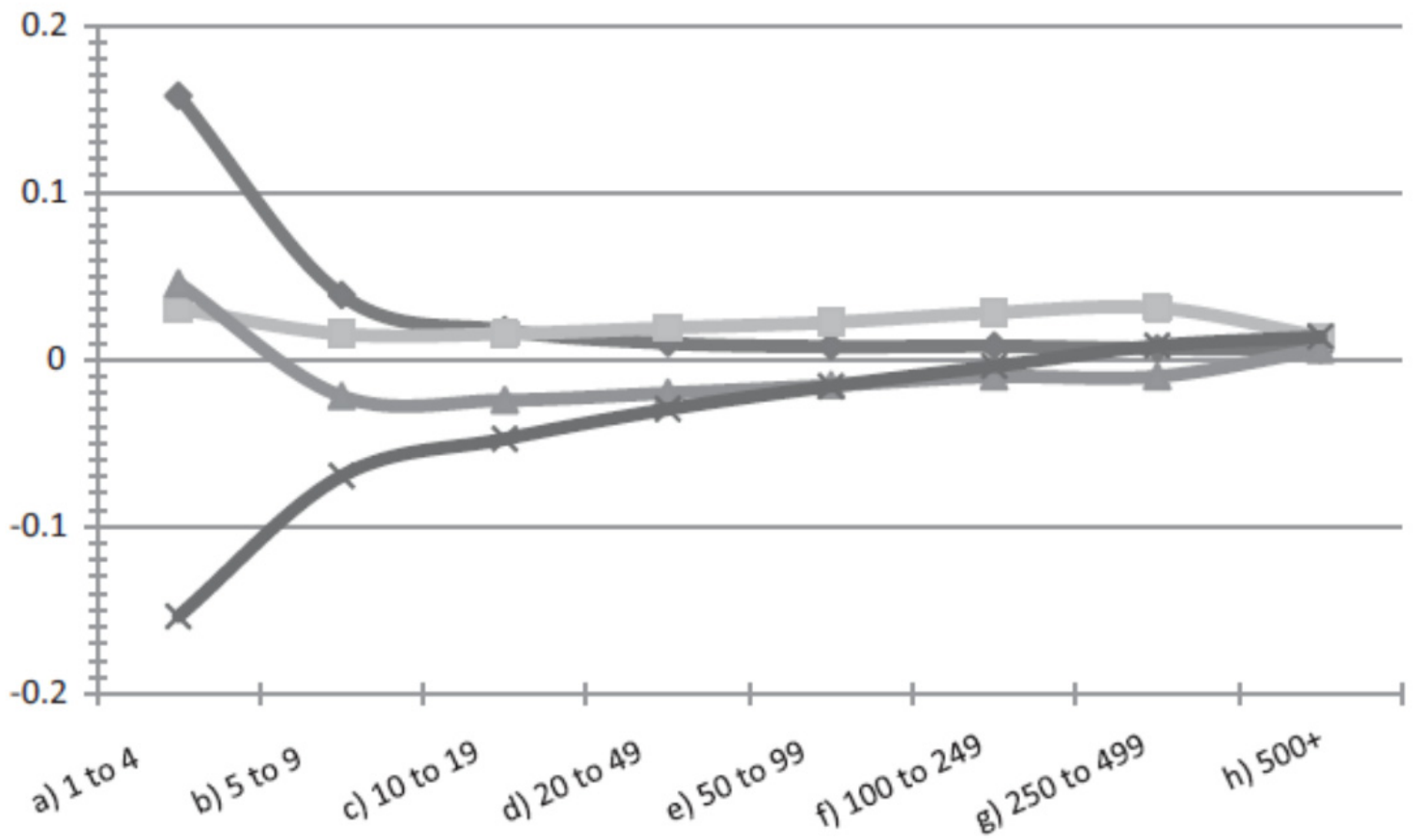

Firm Size Class

_Base Year Size

- Current (Avg) Size

Base Year Size with Age Controls

- Current (Avg) Size with Age Controls

Source: Haltiwanger et al. (2013) - Fig. 2, p. 356 
Figure 4. Net employment growth rates by age - ref. category: firms aged 1

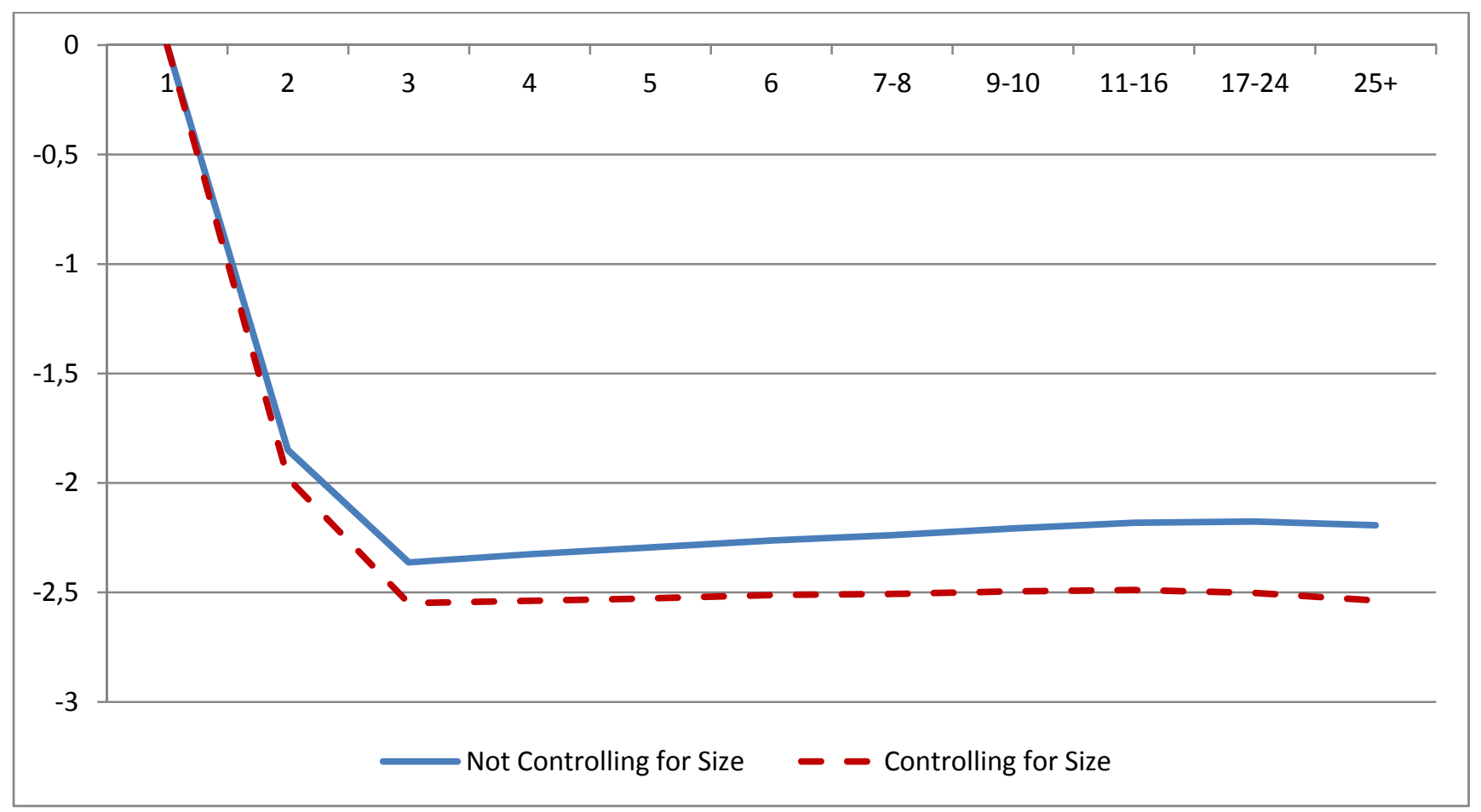

Source: INPS. 
Figure 5. Net employment growth rate by age deciles, controlling for size groups; all firms and survivors only, - ref. category: firms aged 1

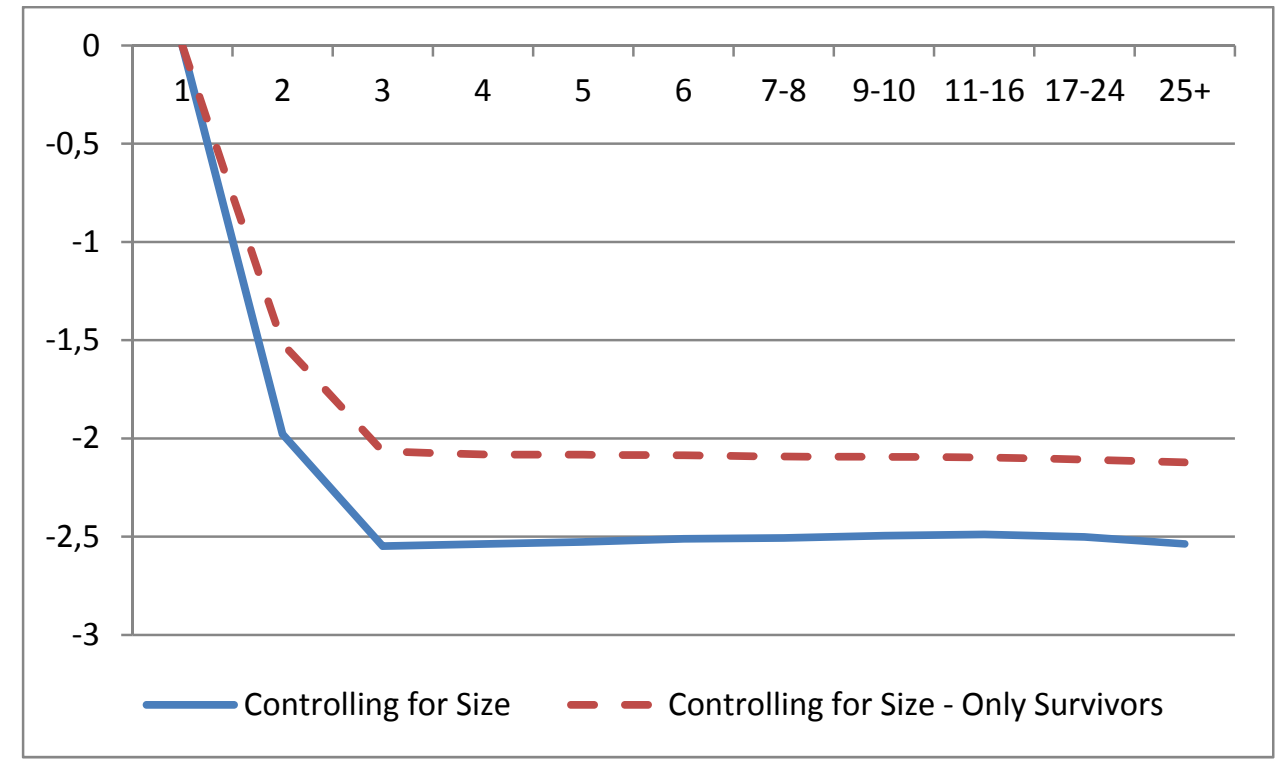

Source: INPS 
Figure 6. Net employment growth rate in the US, ref. category: firms aged 16+.

B. Continuing Firms Only

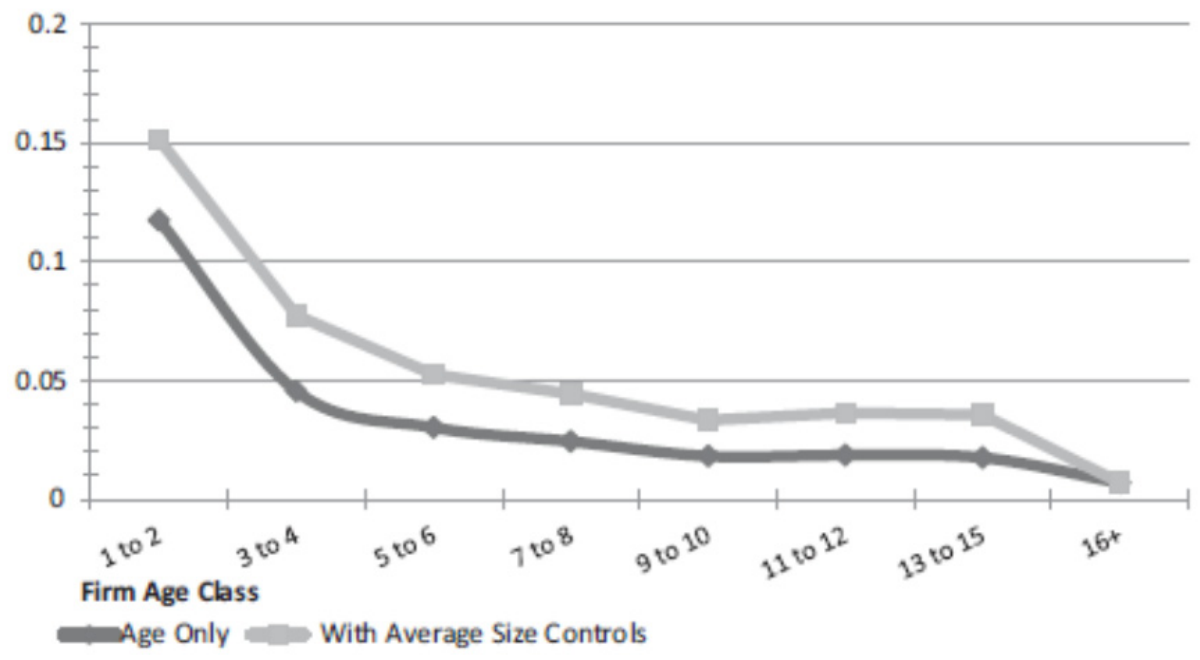

Source: Haltiwanger et al. (2013) - Fig. 4 p. 357 
Figure 7. Exit rate by age -ref. category: firms aged 1 (omitted)

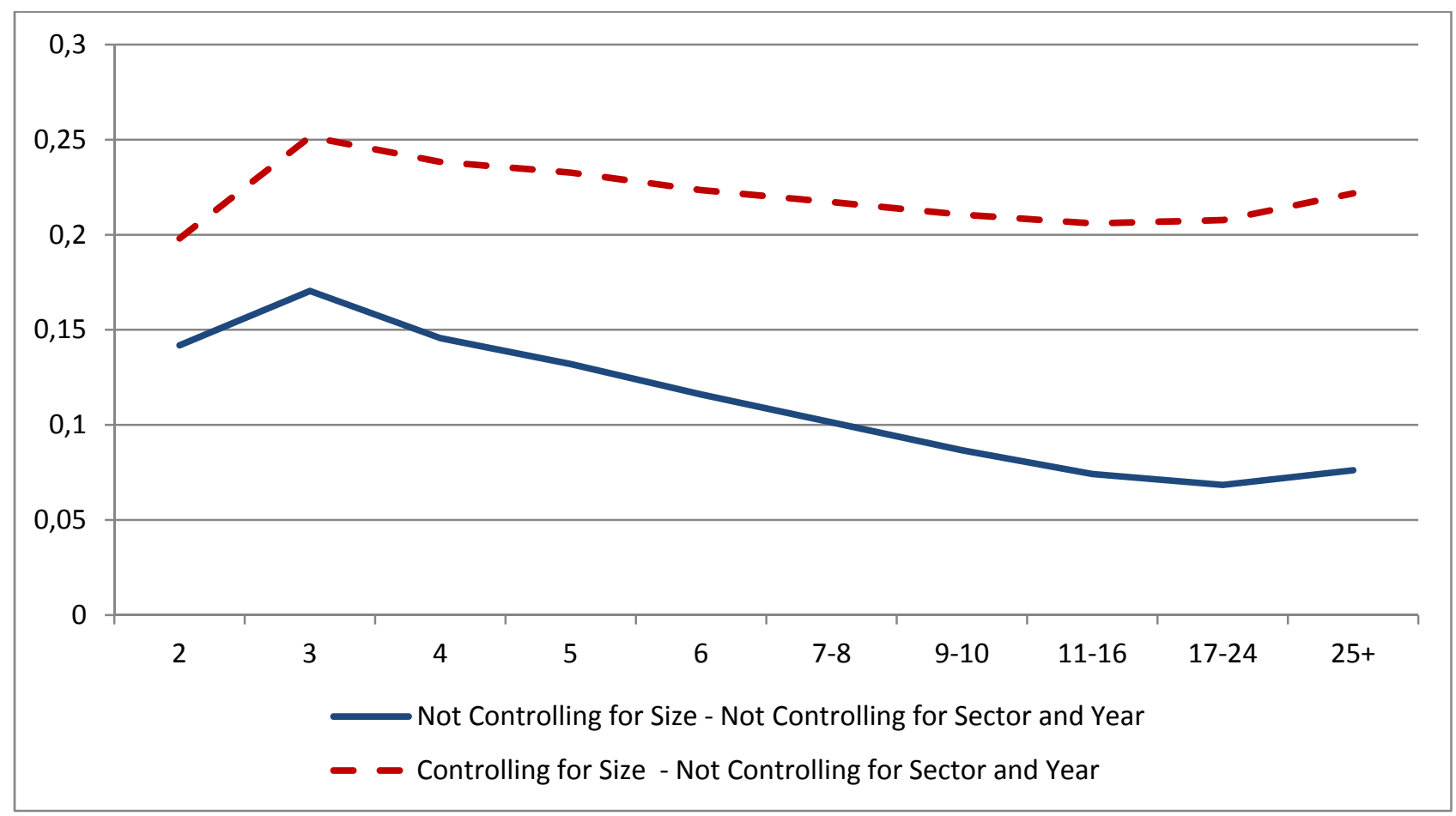

Source: INPS. 
Figure 8. Exit rate by age in the US - ref. category: firms aged 16+

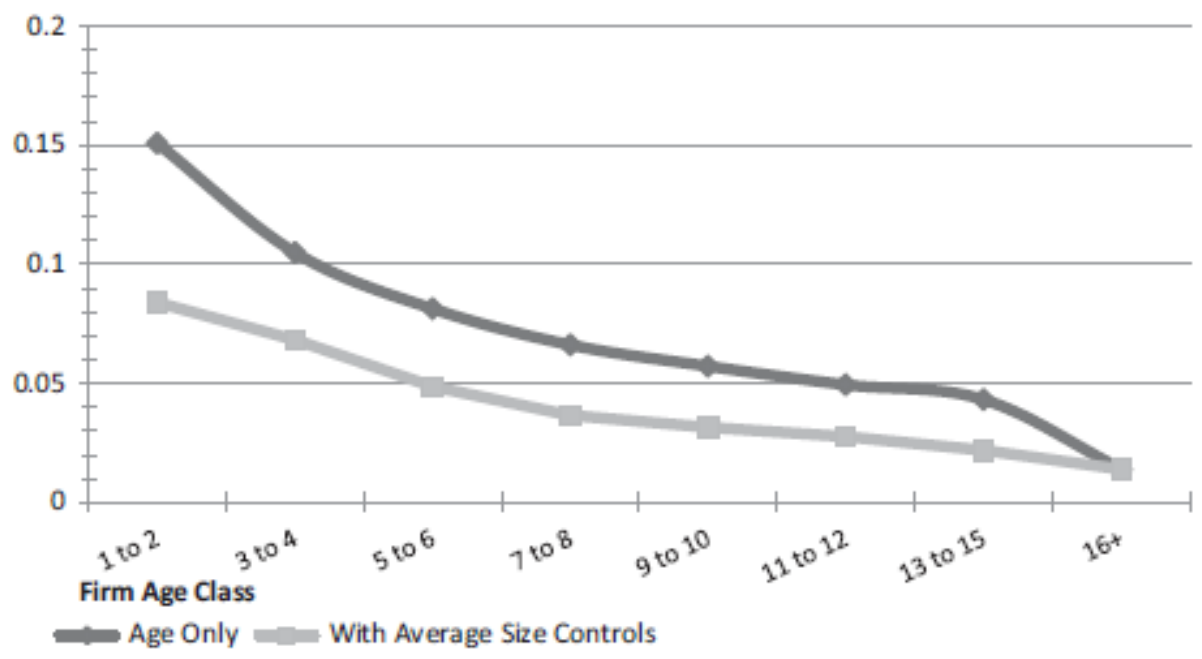

Source: Haltiwanger et al. (2013) - Fig. 5, p. 358

Figure 9 - Exit rates by cohort and age in Italy - 1985-1990

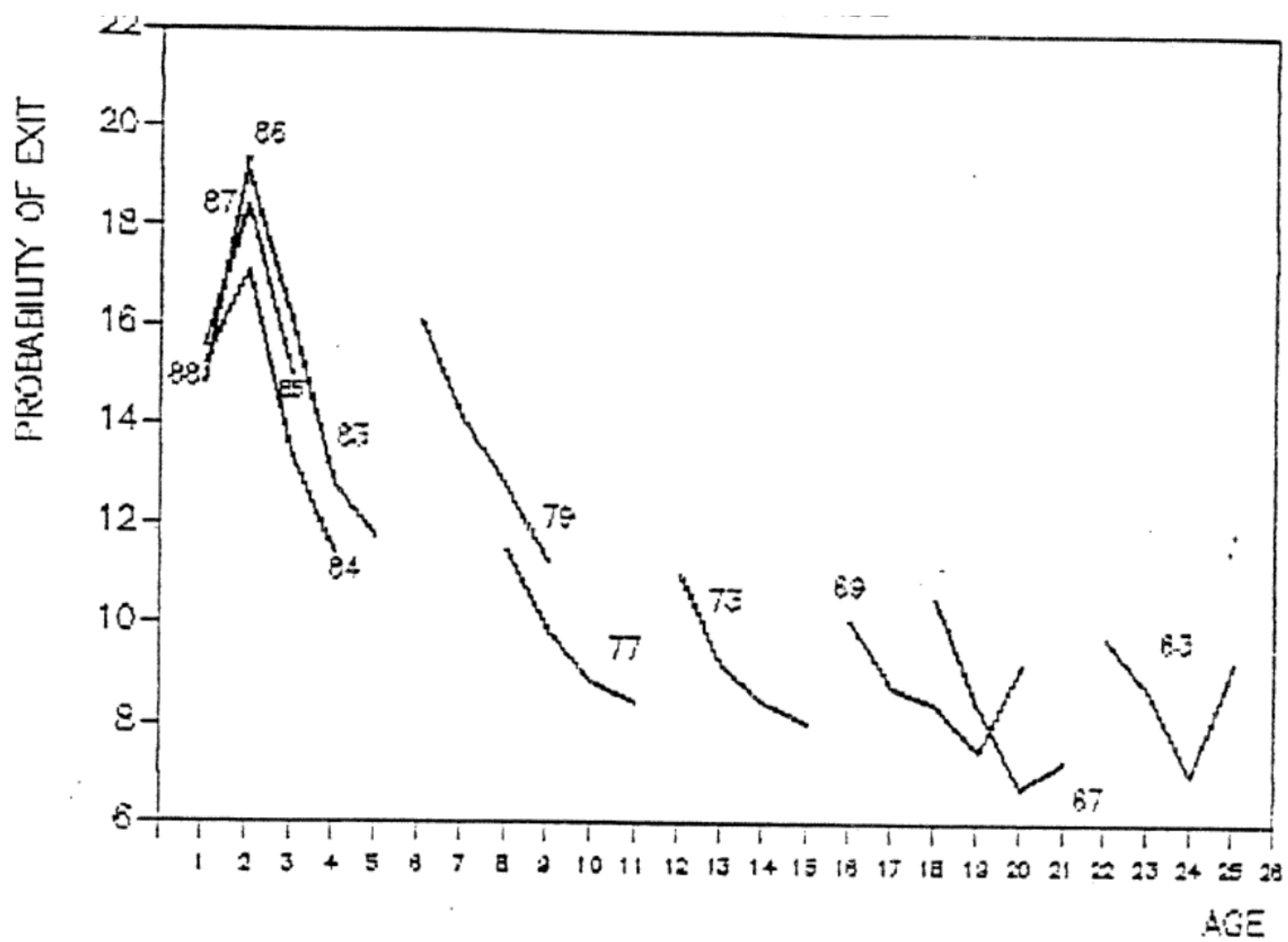

Source: Bianco and Sestito, 1992 - Fig.C 
Figure 10. Net employment growth rates by size during downturns and normal times, controlling for age

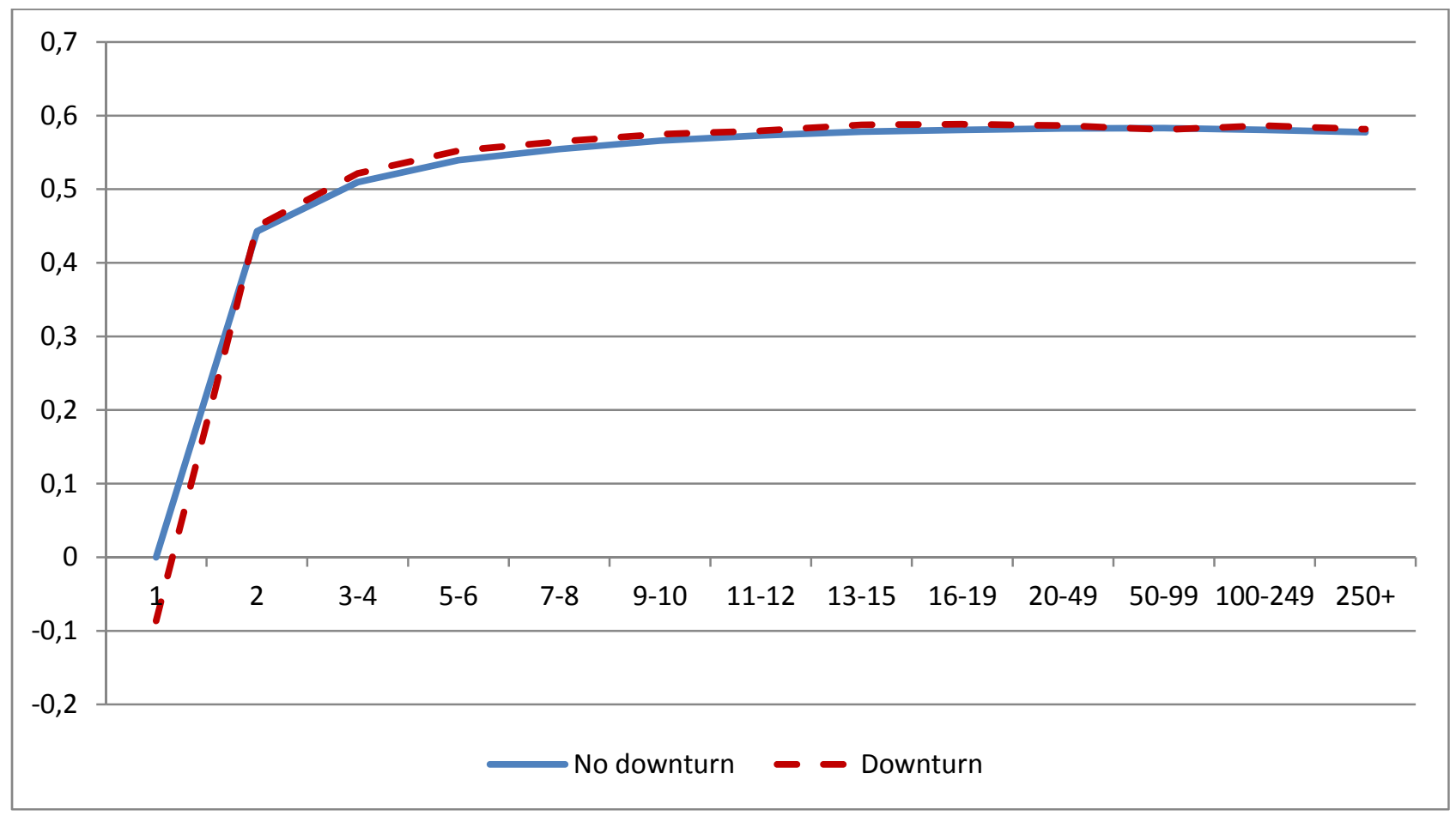

Source: INPS. 
Figure 11. Net employment growth rates by age during downturns and normal times, controlling for size

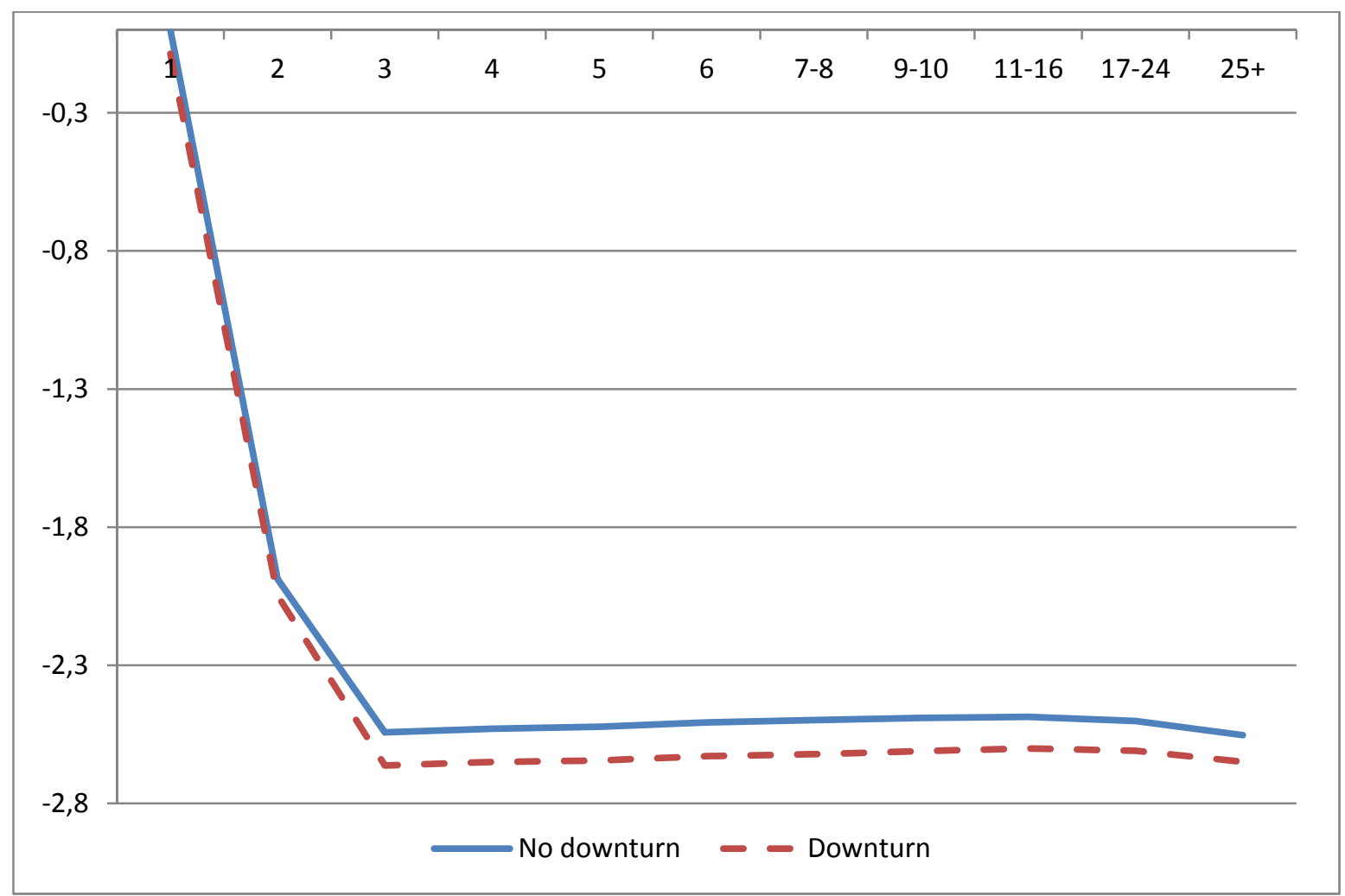

Source: INPS 
Figure 12. Percentage drop in net employment growth rates during downturns by age, controlling for size

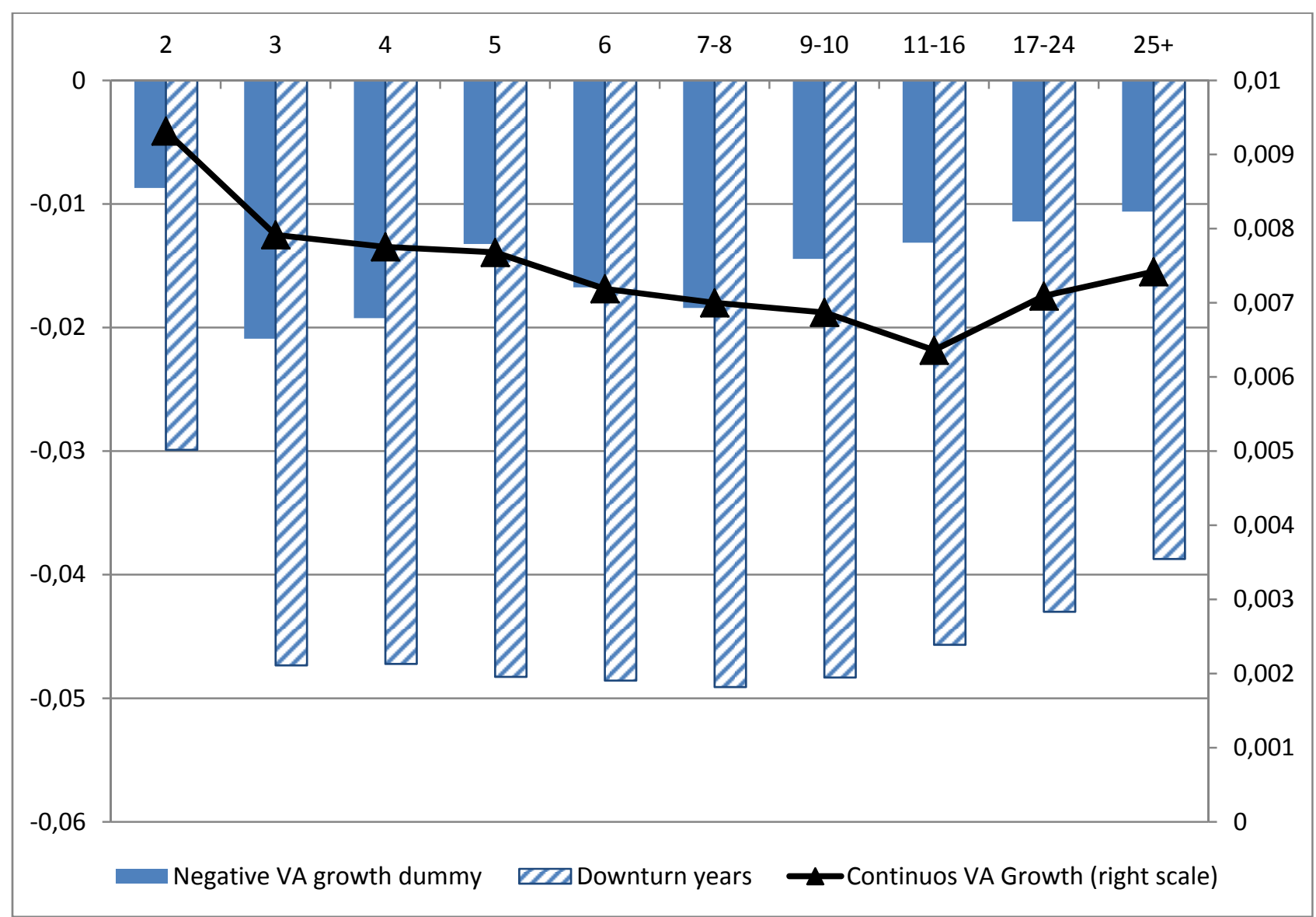

Source: INPS. 
Figure 13. Percentage increase in exit rates during downturns by age, controlling for size

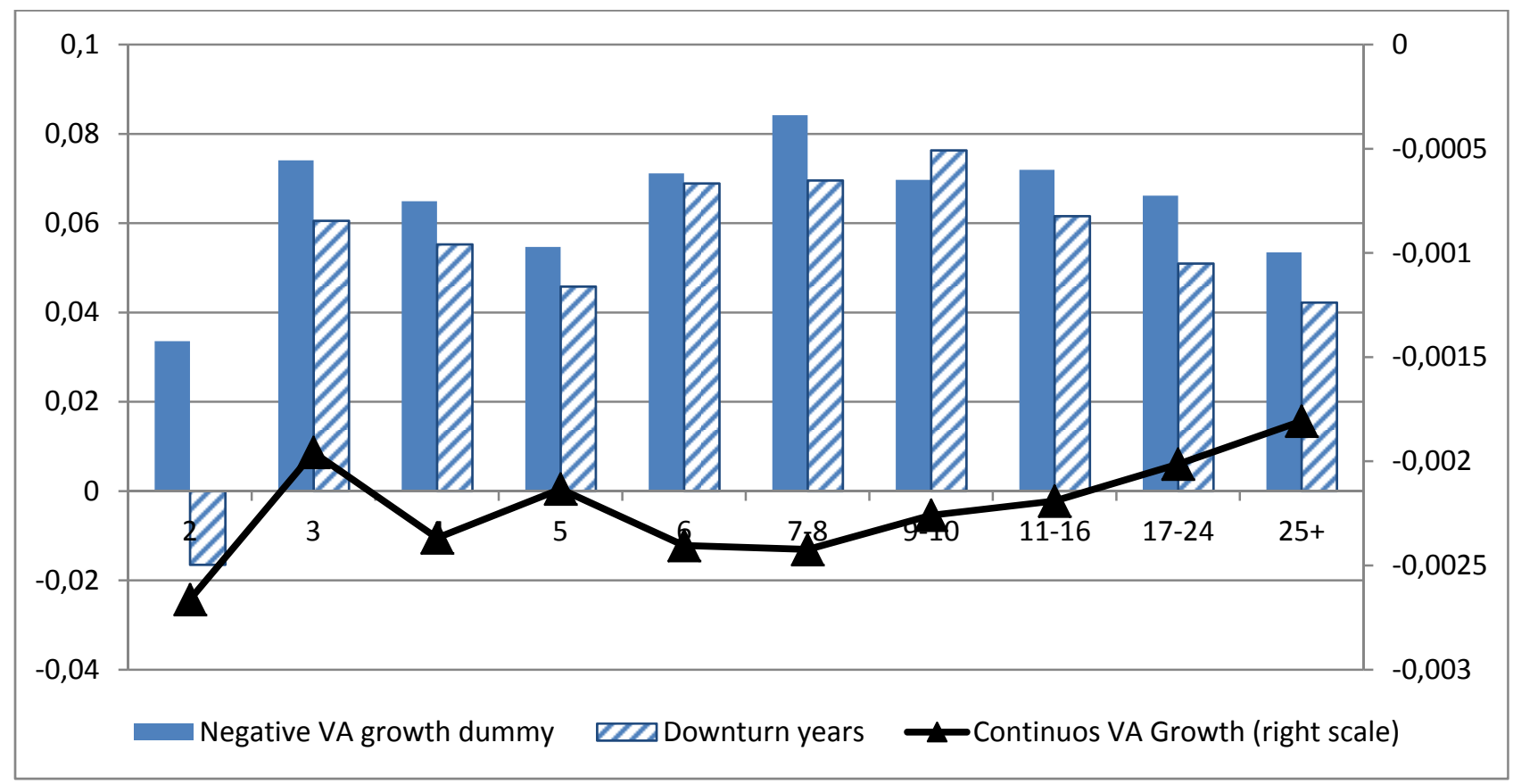

Source: INPS. 